Article

\title{
Are There Differences in the Effects of P-O and P-T Cultural Fits on Work Attitudes and Task Performance? The Moderating Effect of Supportive Leadership
}

\author{
Jee Young Lee ${ }^{1}$ and Yumi Seo ${ }^{2, *}$ (1) \\ 1 Institute of Liberal Arts Education, Hansung University, Seoul 02876, Korea \\ 2 College of Business Administration, University of Seoul, Seoul 02504, Korea \\ * Correspondence: ys263@uos.ac.kr; Tel.:+82-2-6490-2254
}

Received: 23 August 2019; Accepted: 8 September 2019; Published: 17 September 2019

\begin{abstract}
Organizational culture and individual employees' fit with it have been found to be important factors affecting sustainable management. However, the effects of person-team cultural fit (P-T cultural fit) has not been much studied regarding its differential effects compared to other types of person-environment fit (P-E fit). The present study examined how person-organizational cultural fit (P-O cultural fit) and P-T cultural fit have a differential impact on work attitudes and task performance and investigated the moderating role of a team leader's supportive leadership. Using longitudinal data collected from 1539 employees, the results show that P-O cultural fit and P-T cultural fit had a significant positive relationship with organizational commitment, while P-T cultural fit also showed a significant positive relationship with team commitment and task performance. In addition, supportive leadership had significant moderating and enhancing effects on the impact of P-T cultural fit on both organizational and team commitment. As the most proximal unit of individuals' work environment, the congruence between individual and team values plays a crucial role in improving individuals' attitudes and task performance. Our results thus yield practical implications on the importance of team cultural management in the context of sustainable management.
\end{abstract}

Keywords: person-organization cultural fit; person-team cultural fit; team commitment; organizational commitment; task performance

\section{Introduction}

With competitive, uncertain, and dynamic organizational environments on the rise, the importance of keeping employees committed and using their abilities has become increasingly significant in organizations. It is therefore essential to investigate-both theoretically and practically-the factors that make employees devoted to their organization and that improve their performance. Over the last several decades, person-environment fit has consistently received attention, with supporting evidence of its positive effect on employees' attitudes and behaviors [1-7].

In particular, scholars have devoted considerable energy to examining the impact of various types of person-environment fit on differential effects of $\mathrm{P}-\mathrm{O}$ fit in various organizational contexts $[2,8,9]$. These types of person-environment fit can be categorized as person-job fit (P-J fit), person-vocation fit (P-V fit), person-team fit (P-T fit), and person-organization fit (P-O fit), and researchers have thus far compared two or three fit measurements according to different research contexts. Among those studies, a few have examined the empirical evidence of differential effects of various fit measurements $[10,11]$, but most have solely focused on the differential effects of P-J fit and P-O fit $[8,10,12,13]$, as the job is at the core of individuals' work environment, impacting their attitude and behavior, while organizations are rather distal but critical. 
The present study aimed to expand on previous works on multiple fits, considering P-T fit to examine the differential effects it exhibits, as compared to P-O fit. Since the team system was introduced for active and flexible responses to dynamic and complex organizational environments, teams have become the basic and core work units of organizations [14]. In addition to the practical importance of teams as such, existing fit studies have been taking into account the positive effects brought about by the congruence between individuals and teams, which are the minimum work units, under the name of "person-group (P-G) fit" [15] or "P-T fit" [16]. While P-T fit studies have been steadily conducted along with the expansion of teams' field importance $[2,17]$, these studies relatively rarely involved empirical analyses, compared to person-environment (P-E) fit studies. Furthermore, even those studies that involved empirical analyses only examined individual effects and did not consider these in comparison with other fits. Therefore, it is necessary to investigate the effects of the congruence of individuals and their teams as well as the differential effects of P-T fit with other P-E fit measures.

In addition to the increasing importance of teams, organizational studies have also focused on team leadership and changing roles [18]. With horizontal communication and relationships becoming important to quickly cope with changing and dynamic organizational environments, there has been more emphasis on types of leaderships that allow smooth communications and that accept team members' active opinions. In the present study, the moderating effects of supportive leadership was examined focusing on whether team leaders' supportive leadership enhances or replaces P-T cultural fit and P-O cultural fit.

In the context of sustainable management, the importance organizational culture and P-O fit has been found to be an important factor for enhancing employees' attitude towards corporate social responsibility (CSR)activities and task performance $[19,20]$. Oo, Jung, and Park found that P-O fit strengthened the pride and organizational citizenship behaviors relationship explaining why employees perceiving a good fit with their organization will build up a high level of identification with their organizations and engage in extra-role behaviors as well as in-role behaviors. When organizations engage in CSR activities, employees who perceive a good P-O fit will understand the organization's CSR message better and support those with good attitudes [19]. As P-O fit and P-T fit means value consistency with its members, organizations who seeks sustainable management should carefully manage employees' perceived P-O fit and P-T fit, which could be a great amplifier. In addition, Lee and Kim also argued the role of organizational culture in helping to translate CSR into firm performance [20]. They found that the organizational cultures moderated the relationship between CSR and financial outcomes, as a high level of market culture strengthened the positive relationship between CSR and firm performance. When individual employees have a good P-O fit and P-T fit with this type of organizational culture, this relationship will be even stronger.

\section{Theoretical Background}

\subsection{The Effects of P-O Cultural Fit on Individuals' Attitudes and Performance}

Cultural fit is defined as "the extent to which values are shared at different levels of an organization, including individuals" [21]. Since values are considered to be the most important element among those that constitute culture [22], cultural fit is used interchangeably with 'value fit' or 'value congruence' for the same meaning. Thus far, cultural fit has been actively studied in two research strands: P-O cultural fit and P-T cultural fit [23]. P-O cultural fit is the "congruence between the value of individuals and the value of the organization" (e.g., [24-27]), and has been actively studied since the 1990s following a series of studies conducted by O'Reilly and his colleagues [22,28].

In most studies conducted thus far, P-O cultural fit has been reported to positively affect both attitudes toward organizations [29] and attitudes toward individual members themselves [22]. That is, congruence between the values originally held by individuals and the values emphasized by the organization was shown to positively affect organization selection [30], organizational adaptation [31,32], as well as organizational commitment and turnover (e.g., [3,30,33]). 
Cultural fit researchers explain the positive results shown by cultural fit through the similarity attraction theory [34], the social identity theory [35], and the attraction-selection-attraction (ASA) theory. According to the similarity attraction theory, people feel more attraction and positive feelings toward those who are similar to them, and similar people are highly likely to share common experiences or values in life. This theory suggests that similar people and particularly similar values bring about positive effects on individuals through smoother interactions and communication and subsequent positive attitudes toward each other. In the case of an organization, if the value of an individual is similar to the organization's, the individual adopts a positive attitude toward the organization, which is likely to increase organizational commitment (i.e., attachment to the organization) and organizational satisfaction (i.e., the individual's satisfaction with the organization).

Like the similarity attraction theory, the social identity theory also sheds light on the positive effects of similar values. More precisely, the social identity formed by social categorization makes individuals show a positive bias toward in-group members, while perceiving out-group members less favorably. Since the members belonging to the same category are perceived as in-group members, they trust the members more and perceive the members more cooperatively, and individuals belonging to the group perceive their attitudes and behaviors as positive [35].

Based on the existing empirical results of P-O cultural fit studies of varied theoretical backgrounds, the following hypothesis was derived for the present study.

Hypothesis 1a. P-O cultural fit will have a significant and positive effect on organizational commitment.

Existing studies report that $\mathrm{P}-\mathrm{O}$ cultural fit has a positive effect on other job satisfaction, among other organization-related outcome variables $[6,10,22,36]$. With regard to the former, a meta-analysis of $\mathrm{P}-\mathrm{O}$ fit and job attitudes conducted by Verquer et al. [33] mentioned that job satisfaction, which is used to evaluate individuals' degree of satisfaction with their work, could be regarded as a typical outcome variable to evaluate individuals' attitudes toward the organization. This is because it can be measured after evaluating other related aspects, such as annual salary, position, and work environment.

Although there has been no direct empirical study on the effects of P-O cultural fit on individuals' attitudes toward their teams, based on the above grounds, in the present study, P-O cultural fit was also expected to affect attitudes toward teams perceived by individuals, which is not an organization-related variable. A study conducted by Adkins and Caldwell [1] suggested-while mentioning the argument by Boisner and Chatman [37] - that core subcultures contained in an organization can be units that reflect the culture of the entire organization as they include pivotal values related to the organization. An organization's teams are affected by the organization because they are embedded and included in it. Therefore, when the individual values are congruent with an organization's values, the individuals can be expected to hold positive attitudes toward teams belonging to the organization, as well as positive attitudes toward the organization in general. Based on this, the present study established the following hypothesis.

Hypothesis 1b. P-O cultural fit will have a significant and positive effect on team commitment.

Previous studies have empirically tested the effects of P-O cultural fit on performance and attitudes in organizations [38]. Although there were mixed results, $\mathrm{P}-\mathrm{O}$ cultural fit has been proven to have a positive effect on individuals' performance in many studies [8]. Kristof [3] suggested that P-O fit explains task performance and organizational citizenship behavior with a significant degree of variance and evaluated the effect of P-O fit on behavior in organizations as well. In a meta-analysis of the effect of P-O fit on performance by Hoffman and Woehr [39], P-O fit was shown to be significantly and positively correlated with task performance (with a correlation coefficient of 0.26 ). The positive relationship between P-O fit and performance as such can be explained by Argyris' 1957 theory of motives for fit and the recent explanation by Greguras and Diefendorff [8], which described the mechanism behind the positive effect of P-O fit on performance based on the self-determination theory [40]. 
Argyris' theory of motives for fit explained the effects of congruence and incongruence in terms of motives by stating that the congruence between the value of an individual and that of the organization improves motivation at work, while incongruence degrades individuals' motives. Argyris [41] suggested that since motivation is directly related to the performance of tasks, P-O cultural fit can be expected to positively affect the performance of individuals in organizations.

In addition, Greguras and Diefendorff [8] suggest that the mechanism of the self-determination theory can explain the relationship between fit and performance, and explain that the congruence of values can lead to the satisfaction of psychological needs, bringing about positive effects on psychological growth, optimal functioning, and well-being. In particular, they revealed that the prediction of the effects of $\mathrm{P}-\mathrm{O}$ cultural fit on performance is mediated by competence need satisfaction (being an element of the self-determination theory), thereby explaining why P-O cultural fit significantly affects performance. Based on these theoretical and empirical grounds, the following hypothesis was established for the present study.

Hypothesis 1c. P-O cultural fit will have a significant and positive effect on task performance.

\subsection{The Effects of P-T Cultural Fit on Individuals' Attitudes and Performance}

P-T cultural fit refers to the congruence between the value of individuals and that of their team [3]. In this case, the interest lies in the effects of different degrees of similarity between individuals' values and that of their entire work group [22] or that of their colleagues in their work group [42]. Although P-T fit is considered as being included in team diversity, in that the similarity between individuals' and team's characteristics is examined, fit researchers argue that the diversity identified using demographic characteristics is different from fit in terms of variables or measurement methods $[5,18]$. Therefore, in the present study, the effects of P-T cultural fit on individuals will also be examined based on previous fit studies rather than diversity studies.

Although few studies have been conducted on P-T cultural fit, compared to P-O cultural fit [2,5], recently, as teams have been increasingly regarded as important and meaningful to individuals in their lives within organizations, researchers have been considering the effects of the congruence between the values of individuals and the values of their team [2,5,6,43,44]. For instance, Elfenbein and O'Reilly [43] examined the effects of P-T cultural fit on individuals' performance, turnover intentions, and team member liking based on a sample of 114 individuals in 16 teams. In addition, in a study conducted by Adkins et al. [42] with 119 production workers, the effects of cultural fit between individuals and team colleagues on job satisfaction were shown empirically.

A review of extant P-T fit studies showed that similar to the findings of other studies on P-E fit, P-T cultural fit has a positive effect on job satisfaction $[2,8,45]$ and task performance $[1,2,5,42,45]$. In addition, P-T cultural fit has a positive effect on team-related variables, such as positive feelings toward team members [43] or team commitment [5], also shown by empirical results.

In addition, P-T cultural fit is expected to have a positive effect on individuals' attitudes and behavior toward other individuals and teams in the organization, as well as the general attitude toward their organization. This is supported by a meta-analysis conducted by Kristof-Brown et al. [2], which showed a significant and positive relationship between P-T cultural fit and organizational commitment. Since teams are the units embedded in an organization [14] to achieve its goals and performance, they can be said to include and represent the attributes of the organization. Therefore, the congruence of individuals' values with that of their team can be expected to make the individuals hold positive attitudes toward not only their team but also their organization. Therefore, in the present study, based on these grounds, the following hypotheses were established.

Hypothesis 2a. P-T cultural fit will have a significant and positive effect on organizational commitment.

Hypothesis $\mathbf{2 b}$. P-T cultural fit will have a significant and positive effect on team commitment. 
Hypothesis 2c. P-T cultural fit will have a significant and positive effect on objective task performance.

\subsection{The Differential Effects of P-O Cultural Fit and P-T Cultural Fit}

Most studies on cultural fit conducted thus far have been dealing with P-O and P-T cultural fits independently $[22,27,46]$. Recently, however, as fit studies continue to evolve, some have centered on perceived fit, looking at the differential effects of fits (e.g., [3,10-12,32].

For instance, in a study of the convergence validity and discrimination validity of fits conducted with 187 organization leaders, Cable and DeRue [12] reported that whereas P-O fit was associated with organization-related outcome variables, such as organization identification, organization citizenship behavior, and turnover intentions, person-job fit affected job-related variables, such as job satisfaction, career satisfaction, and job commitment, thereby reporting differential relationships. In a longitudinal study conducted by Saks and Ashforth [32], in which 113 college graduates were studied, person-job fit significantly affected job satisfaction, organizational commitment, organization identification, stress, and turnover intentions, whereas P-O fit only significantly affected turnover intentions and turnover rates, thereby confirming the differential effects of the two fits. A study conducted by Shin indicated that team-level PO fit predicted team-level organization citizenship behavior better than team-level efficacy [11]. They also pointed out that team-level person-job fit is a predictor variable significant only for team efficacy, thereby empirically showing the differential relationships between fits and outcome variables.

A review of the results of these studies shows that $\mathrm{P}-\mathrm{O}$ fit has a stronger connectivity to those attitudes that are directly related to the organization because the subject of congruence with individuals' values is the organization. In addition, following the same logic, P-T fit has a stronger connectivity to those attitudes that are directly related to the team because the subject of congruence with individuals' values is the team. Therefore, based on the results of existing studies, the following hypotheses were established.

Hypothesis 3a. $P$-O cultural fit will have a stronger positive relationship with organizational commitment than P-T cultural fit.

Hypothesis $3 \mathbf{b}$. P-T cultural fit will have a stronger positive relationship with team commitment than P-O cultural fit.

What would be the differential effects on task performance? Although not directly related to task performance, Adkins and Caldwell [1] focused on a similar question regarding the outcome variable of job satisfaction, directly comparing the effects of P-O cultural fit and of P-T cultural fit on job satisfaction through the realistic cultural fit measurement method of organizational culture profile (OCP) with 136 consultants. According to them, since organizations are gradually changing to have virtual shapes and autonomous teams, and lifelong organizations are being replaced by lifelong occupations, it is becoming increasingly difficult for individuals to have one culture in the entire organization. Thus, they predicted that P-T cultural fit would more strongly impact job satisfaction, as compared to P-O cultural fit, because individuals' lives within their teams, which are directly related to their jobs, were becoming more important than their lives within the organization [47].

This can also be supported by the results of existing studies on P-T cultural fit. In a meta-analysis conducted by Kristof-Brown et al. [2], a significant and positive relationship between P-T fit and task performance was reported, and a study conducted by Seong et al. [5] proved that value-based P-T fit predicted performance while showing a significant and positive relationship with task performance. A study conducted by Adkins et al. [42] also empirically tested the relationship between P-T value fit and performance, showing that value fit among colleagues significantly affects objective performance evaluated by superiors when task interdependence is high. Based on these results, the following hypothesis was established. 
Hypothesis 3c. P-T cultural fit will have a stronger positive relationship with task performance compared to P-O cultural fit.

\subsection{The Moderating Effects of Supportive Leadership}

Supportive leadership is defined as the behaviors of leaders of providing emotional support to and expressing interest in members' needs and welfare [48]. This is similar to the individualized consideration, a sub-dimension of transformational leadership, which is to express interest in individual members and responsibly attend to their personal needs [48]. The supportive role and empowerment of leaders is receiving more attention as such behavior of leaders who have considerable effects on individuals is becoming increasingly important to maximize individual capacities through quick responses in dynamic and complex organizational environments [49].

Although existing P-E fit studies have not directly addressed the moderating effects of supportive leadership, some studies have empirically tested whether leader-member exchange (LMX) [50], perceived organization support (POS) [51], and social support [51] —which are similar to supportive leadership - have moderating effects in the relationship between P-E fit and task outcomes.

For instance, a study conducted by Erdogan et al. [50] with 253 teachers at 30 schools suggested that when the quality of LMX is high, even a low P-O value fit can be offset. They empirically tested whether LMX can act as a moderating variable in the effects of $\mathrm{P}-\mathrm{O}$ fit on career satisfaction and job satisfaction. In addition, in a recent study on 213 bank employees by Maden and Kabasakal [51], POS was shown to have a moderating role on the effects of organization and job, and superior fits on members. According to them, POS helps increase communication and cooperation among organization members [52], thereby enhancing members' sense of belonging and trust in the organization, which leads to the satisfaction of members' socio-psychological needs. In addition, it was suggested that in a highly supportive organizational environment, high satisfaction can be maintained even when job satisfaction is low, because members feel stability and satisfaction with their work.

As examined above, the moderating effects of supportive environments claimed in existing studies are hypothetically explained by the fact that when P-E fit is incongruent or unsatisfactory, if the leader or environment that can affect the individual is supportive, the individual can feel satisfaction. That is, these variables are contextual elements that commonly surround individuals and can be said to have the potential to help them maximize their abilities or support them in adapting to insufficient or unsatisfactory conditions.

Based on these findings, the present study suggests that supportive leadership can also play a role in moderating the effects of P-E fit as with LMX, POS, and social support proposed in existing studies [48]. Team leaders are meaningful contextual variables that affect team members' attitudes and behaviors [53]. In particular, the supportive leadership proposed in the present study has also been reported consistently as a variable that positively affects organization members (e.g., [54-56]). For instance, Rafferty and Griffin [57] demonstrated that supportive leadership positively affects members' satisfaction, commitment, and career certainty. Cohen and Wills [58] reported that a leader's social support has a buffering effect against members' job-related stress. Therefore, based on these previous findings, the present study suggests that supportive leadership plays a role in reinforcing positive effects on members while countering negative effects.

Along with job attitudes, in the present study, task performance is also expected to be influenced by supportive leadership. Although the consideration for and interest in members involved in supportive leadership is believed to satisfy members' emotional needs [48,59], supportive behaviors, such as interest, consideration, and care, are also expected to have positive effects on problem-solving and difficulties in organizations. Several recent studies have found that LMX based on social supportive aspects (e.g., caring, trust) has significant and positive effects on members' task performance (e.g., [60]).

Therefore, based on these theoretical and empirical grounds, the present study suggests that supportive leadership can mitigate negative effects related to the incongruence between individuals' values and that of the organization. It will also further strengthen the positive effects 
related to the congruence between individuals' values and that of the organization, leading to the following hypotheses.

Hypothesis 4. Supportive leadership will control the effects of P-O cultural fit and P-T cultural fit on the attitude and task performance of organization members. That is, supportive leadership will play the role of further strengthening the positive effect of P-O cultural fit and P-T cultural fit on an organization's members.

Hypothesis 4a. Supportive leadership will control the effects of P-O cultural fit on (1) organizational commitment, (2) team commitment, and (3) task performance. That is, supportive leadership will further strengthen the positive effect of $\mathrm{P}-\mathrm{O}$ cultural fit on an organization's members.

Hypothesis $4 \mathbf{b}$. Supportive leadership will control the effects of P-T cultural fit on (1) organizational commitment, (2) team commitment, and (3) task performance. That is, supportive leadership will further strengthen the positive effect of $P$-T cultural fit on an organization's members.

\subsection{The Differential Moderating Effects of Supportive Leadership}

What differential effects will the moderating role of supportive leadership have on the effects of multiple fits? The notion of supportive leadership used in the present study refers to the supportive behaviors adopted by team leaders $[48,60]$. Since team leaders represent the positions of their team within the organization and also play the role of distributing the resources, manpower, and time within their team, they are in charge of boundary management, which can affect their team, both internally and externally $[18,61]$. Therefore, the supportive role of team leaders can both affect team members' attitude toward the organization and their attitude toward the team.

Therefore, we assumed that the supportive leadership of team leaders would play a more important role in team members' within-team attitudes and behaviors. A team leader is a representative of his/her team and can be said to represent the team per se. In addition, team leaders also share many things physically and emotionally with team members. Therefore, team leaders' supportive leadership is expected to be more influential for team-level attitudes compared to organization-level ones.

Although few studies focused on the differential effects on individuals' attitudes toward their teams and their organizations, some studies looked at the differential effects of team commitment and organizational commitment based on the concept of commitment [62,63]. Using longitudinal data obtained from three surveys, Neininger et al. [63] empirically showed the strong effects of organizational commitment on organization-related variables (job satisfaction and turnover intention), finding that team commitment has stronger effects on team-related variables (performance and colleague altruism) [63]. Such results were based on the "theory of reasoned action" [64]. This theory suggests that individual behaviors are induced by behavior intentions, which are led by individual attitudes toward behaviors. That is, the theory argued that team-related behaviors can be determined by team-related intentions and attitudes.

Based on these theoretical and empirical results, in the present study, team leaders' supportive leadership is expected to have the strongest effect on the impact of P-T value fit (related to team-level dynamics) on members' attitudes toward the team. The final research model based on our hypotheses is shown in Figure 1.

Hypothesis 5. Team leaders' supportive leadership will have a stronger impact on the moderating effects of P-T cultural fit on team commitment, compared to the moderating effects of P-O cultural fit on organizational commitment. 


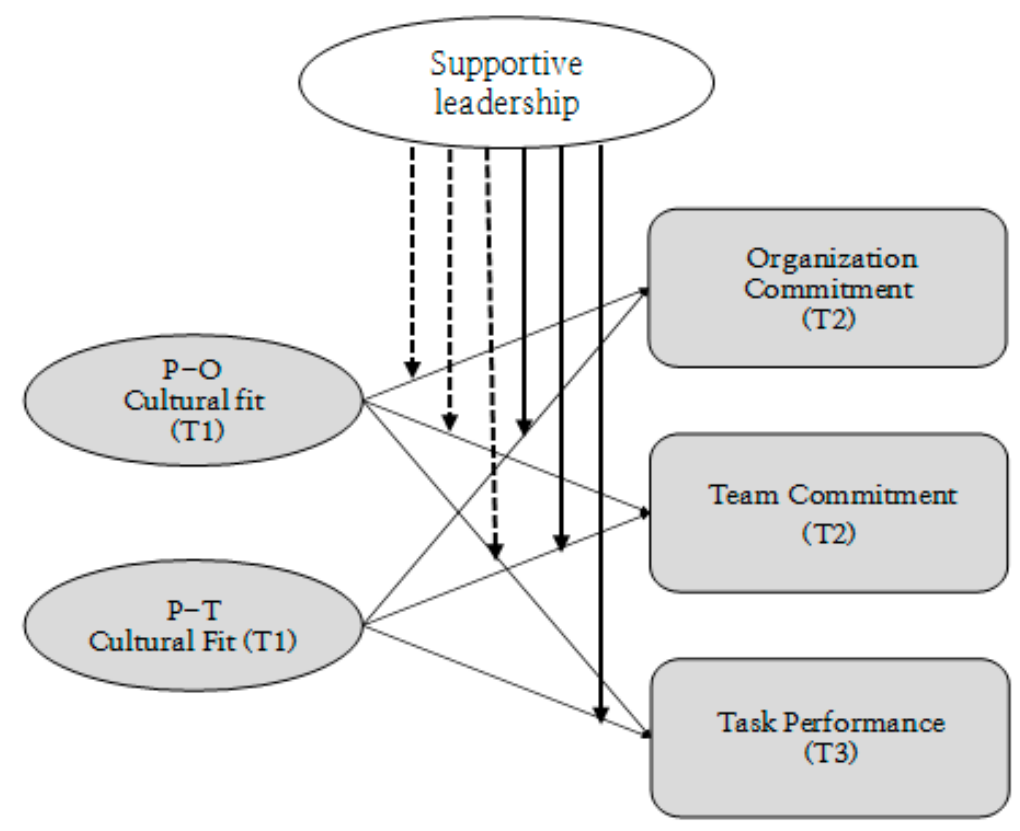

Figure 1. Differential effect model for P-O culture fit and P-T cultural fit.

\section{Method}

\section{Sample and Data Collection Procedure}

The data in the present study were collected from large multinational engineering companies in South Korea. Engineering is "the act of creating economically useful tangible and intangible goods by utilizing given resources and expertise in scientific technologies" In the "Practical Guide for Overseas Expansion of Engineering" compiled by the Ministry of Science and Technology (2002), engineering is characterized by the fact that it manages and leads the process through which intangible goods ranging from design, procurement, and construction to project management are changed into tangible goods. Because of these characteristics, engineering services can create high performance only when the teams or individuals that play many functional roles cooperate and collaborate toward one task. The specific business fields analyzed in this study were hydrocarbon, oil refining, gas, petrochemical plants, electric power, and water treatment plants. These organizations consist of engineering process-based function-centered team structures.

The data were collected four times, through three surveys and one round of performance data acquisition. The first survey (T1) was conducted in July 2011 under the name "organizational culture diagnostic survey", and 3014 out of 5931 (the total number of persons in the target companies) individuals responded to the questionnaire (response rate of 50.8\%). The second survey (T2) was conducted in September 2011, and 3342 members, 56.3\% of the entire sample, responded to the questionnaire. The third survey (T3) was conducted in November within the framework of a workshop addressed to all employees to measure the baseline of satisfaction with and commitment to the team before the workshop. Here, 2130 members, that is, $35.9 \%$ of the sample, responded.

In the three surveys, 1539 members of 181 teams commonly responded to all questionnaires, and these were selected as final data for the analysis. There were 52 teams in the management support group, 11 teams in the marketing and sales group, 37 teams in the external business group I, 31 teams in the external business group II, and 50 teams in the domestic business group. Team size varied from 3 to 20, and each employee's team tenure and team size were included in the model as control variables.

As for the numbers of respondents by position in the organizations, the number of staff members was 595 , accounting for $39 \%$ of the entire sample, while assistant managers, section managers, deputy department managers, and department managers accounted for $23 \%, 15 \%, 14 \%$, and $9 \%$ of the entire sample, respectively. Thus, the position distribution has ratios similar to those of the position 
composition of the organizations. Of all the participants, 192 were female, accounting for only $12 \%$ of the entire sample. Regarding education levels, $74 \%$ of the respondents had a bachelor's degree and $17 \%$ had a master's or a doctoral degree. Among the job groups, the design job group accounted for the highest ratio, with 882 respondents $(57.3 \%)$. Among the remaining six job groups, the ratio of employees in the management support was the highest (256 individuals, $16.6 \%$ ), followed by procurement (160 individuals, $10.3 \%$ ), project (81 individuals, $5.2 \%$ ), construction work (60 individuals, $3.8 \%$ ), marketing and sales (53 individuals, $3.4 \%$ ), and research \& development (47 individuals, $3 \%$ ), in the order of precedence.

\section{Measurement}

\subsection{Organizational and Team Culture in Engineering Companies}

A Korean translation of the organizational culture assessment instrument (OCAI) scale by Cameron and Quinn [46] was used to measure and analyze organizational and team culture. This scale is based on the competing value frameworks (CVFs). Although the CVF is a tool most frequently used in organizational culture studies [65], it is also used and applied when measuring subcultures, such as team culture. When measuring organizational culture, terms, such as "our company" and "our organization", were used in a way that evaluation would be carried out based on organizations, and when measuring team culture, terms, such as "our team", were used so that evaluation would be carried out based on teams. The OCAI consists of six subjects (overall atmosphere, leadership, behavioral styles of members, pivot factors in organizations, core values of organizations, and performance evaluation index), and each subject requires answers to four value items. Therefore, the OCAI consists of a total of 24 items.

As for the rating method, the method in the original text of Cameron and Quinn (2006) was applied; the respondents were asked to allocate 100 points per item in four competitive values: Community culture, innovation culture, market culture, and hierarchical culture [46]. For instance, statements indicating four different characteristics are presented for a question, such as "What is the overall atmosphere of our company?" Individuals were asked to divide 100 points to allocate a score to each statement, indicating what they think of their company or team. For example, if their company is currently run in a family-like atmosphere, they can assign 55 out of the 100 points to the relevant statement and the remaining 45 points to the remaining statements. This is a compulsory assignment, which is useful for diagnosing dominant organizational cultures, and since 100 points are allocated to four values, the allocation can prioritize the values.

\subsection{P-O Cultural Fit (T1)}

As for P-O cultural fit, the method presented by Adkins and Caldwell [1] was applied to calculate the fit index through the correlation between the organizational culture regarded to be desirable in the future and the current one $[22,66,67]$. That is, the individual culture considered desirable by individuals was regarded as reflecting the value of individuals and assumed to be the "individual's value". In addition, the current organizational culture was assumed to be the "organization's value". Thereafter, the index created with the correlation between the two values was defined as the P-O cultural fit. Since the CVF was designed to rate six dimensions, the mean values of the six items were calculated and used.

\subsection{P-T Cultural Fit (T1)}

P-T cultural fit was calculated in the same way as P-O cultural fit. After calculating the mean values of six items in six dimensions considered desirable in the future-by applying the methods of Adkins and Caldwell - the fit index was calculated through the correlation between the future team culture and the current one $[1,22,66,67]$. 


\subsection{Organizational Commitment (T2)}

Organizational culture was measured using three items corresponding to affective commitment, based on the items for organizational commitment by Allen and Meyer [68]. Representative items included "I feel proud of my organization" and "If someone criticizes my organization, I feel like I am criticized." These items showed a reliability value of 0.90 .

\subsection{Team Commitment (T2)}

Team commitment was measured using the three items developed by applying the affective organizational commitment presented by Allen and Meyer [68]. Example items included "I feel a strong sense of belonging in my team". These items showed a reliability value of 0.89 .

\subsection{Objective Task Performance (T3)}

The task performance of members was measured using the key performance index (KPI), commonly used in organizations [69]. This index reflects the evaluation of the immediate superior, which can be revised by the superior of the immediate superior after review. This index is said to be of good quality as it is an objective index actually used in organizations, unlike subjective evaluation indexes generally based on scales. The KPI typically consists of an "achievement appraisal" related to how well the person has performed on a given assignment and a "competence appraisal" related to the potential and capacity of the person. References to task performance generally mean the average of both appraisals. The score is composed of a full score of 10 points, and usually means 5 points.

\subsection{Supportive Leadership (T1)}

Team members evaluated the degree of leaders' supportive leadership by applying all three items developed by House [70] and used by Rafferty and Griffin [48]. Examples of items include "When conducting behaviors that may affect me, my team leader considers my emotions" and "My team leader reads my personal needs well". These items showed a reliability value of 0.93 .

\subsection{Control Variables (T3)}

Analyses were conducted after controlling for organization tenure, education level, position level, gender, marital status, team size, and team tenure, which were considered to affect individual satisfaction in the target companies. Team size might reflect inter-team dynamics, such as mutual monitoring [5] and other interactions between team members that could affect the effect of P-T fit $[5,71,72]$, which was therefore included as a control variable. The organization tenure, team size, and team tenure, which are continuous variables, were obtained from personnel data provided by the organizations, while education level $(1=$ high school graduation, $2=$ junior college graduation, $3=$ college graduation, $4=$ master's degree graduation, $5=$ doctorate graduation), position level ( 1 = staff member, $2=$ assistant manager, $3=$ section manager, $4=$ department manager, $5=$ executive), gender $(0=$ female, $1=$ male $)$, and marital status $(0=$ unmarried, $1=$ married $)$, which were originally categorical variables, were converted into continuous variables by encoding them before being used.

\section{Results}

Table 1 presents the descriptive statistics and correlations of the main variables. The descriptive statistics are presented in the following order: Demographic variables, fit variables, and outcome variables. The mean of the organization tenures was $64(\mathrm{SD}=5.53)$, indicating that the average respondent worked for at least three years in the organizations, a time during which they could adapt to their organizations and could be socialized, to some extent. The mean education level was a bachelor's degree $(M=3.06, S D=0.66)$. Regarding gender, males were predominant, with ratios of about $88 \%$. The mean $\mathrm{P}-\mathrm{O}$ cultural fit was $-0.14(\mathrm{SD}=0.64)$, while the mean $\mathrm{P}-\mathrm{T}$ cultural fit was $0.25(\mathrm{SD}=0.68)$. 
It can be said that the respondents tended to report bad P-O cultural fits on average, while P-T cultural fit was usually good.

When the correlations between the variables were reviewed, tenures showed significant positive correlations with position level $(r=0.53, p<0.001)$, gender $(r=0.11, p<0.001)$, team tenure $(r=0.34$, $p<0.001)$, supportive leadership $(r=0.09, p<0.01)$, organizational satisfaction $(r=0.06, p<0.01)$, and task performance ( $r=0.42, p<0.001$ ), indicating that higher tenures were associated with higher position levels, higher ratios of males, longer team tenures, and higher organizational satisfaction and task performance. The educational levels showed significant negative correlations with P-O cultural fit $(r=-0.09, p<0.01)$ and P-T fit $(r=-0.07, p<0.01)$. This could indicate that individuals with higher education levels seek more changes in the current organizational culture or team culture. P-O cultural fit showed significant positive correlations with P-T cultural fit $(r=0.37, p<0.001)$, organizational commitment $(r=0.37, p<0.001)$, organizational satisfaction $(r=0.37, p<0.001)$, team satisfaction $(r=0.37, p<0.001)$, and team commitment $(r=0.37, p<0.001)$, while P-T cultural fit showed significant positive correlations with supportive leadership $(r=0.37, p<0.001)$, organizational satisfaction $(r=0.37, p<0.001)$, organizational commitment $(r=0.37, p<0.001)$, team satisfaction $(r=0.37, p<0.001)$, and team commitment $(r=0.37, p<0.001)$.

Table 1. Descriptive statistics and correlations of major variables.

\begin{tabular}{|c|c|c|c|c|c|c|c|c|c|c|c|c|c|}
\hline & Mean & SD & 1 & 2 & 3 & 4 & 5 & 6 & 7 & 8 & 9 & 11 & 13 \\
\hline 1. Tenure & 5.64 & 5.53 & & & & & & & & & & & \\
\hline $\begin{array}{l}\text { 2. Education } \\
\text { level }\end{array}$ & 3.06 & 0.66 & 0.02 & & & & & & & & & & \\
\hline $\begin{array}{l}\text { 3. Position } \\
\text { level }\end{array}$ & 2.34 & 1.36 & $0.53 * *$ & 0.05 & & & & & & & & & \\
\hline 4. Gender & 0.88 & 0.33 & $0.11 *$ & $0.09 * *$ & $0.23 * *$ & & & & & & & & \\
\hline $\begin{array}{l}\text { 5. Marital } \\
\text { status }\end{array}$ & 0.64 & 0.48 & -0.02 & 0.04 & $-0.11 * *$ & -0.04 & & & & & & & \\
\hline 6. Team size & 14.24 & 9.44 & $-0.13 *$ & -0.04 & -0.04 & -0.01 & $0.37 * *$ & & & & & & \\
\hline $\begin{array}{l}\text { 7. Team } \\
\text { tenure }\end{array}$ & 3.63 & 1.51 & $0.34 * *$ & -0.03 & $0.45^{* *}$ & 0.07 * & 0.03 & $0.11^{* *}$ & & & & & \\
\hline 8. P-O fit & -0.14 & 0.64 & 0.00 & $-0.09 * *$ & -0.01 & 0.00 & 0.06 & 0.04 & -0.05 & & & & \\
\hline 9. P-T fit & 0.25 & 0.68 & 0.01 & $-0.07 * *$ & -0.04 & -0.02 & $0.12 * *$ & 0.01 & $-0.08 *$ & $0.37^{* *}$ & & & \\
\hline $\begin{array}{l}\text { 11. Org. } \\
\text { commitment }\end{array}$ & 4.23 & 0.66 & 0.05 & $-0.07^{* *}$ & $0.11 * *$ & $0.08 *$ & -0.05 & 0.00 & 0.04 & $0.14^{* *}$ & $0.17^{* *}$ & & \\
\hline $\begin{array}{l}\text { 13. Team } \\
\text { commitment }\end{array}$ & 3.95 & 0.77 & 0.00 & $-0.08^{* *}$ & 0.06 & $0.07^{*}$ & $0.13 * *$ & 0.05 & -0.04 & $0.15^{* *}$ & $0.26^{* *}$ & $0.66^{* *}$ & \\
\hline $\begin{array}{c}\text { 14. Task } \\
\text { performance }\end{array}$ & 5.99 & 1.25 & $0.42 * *$ & $0.09 * *$ & $0.43^{* *}$ & $0.09 * *$ & -0.05 & $-0.13^{* *}$ & $0.28^{* *}$ & 0.02 & 0.05 & 0.00 & -0.02 \\
\hline
\end{tabular}

\section{Hypothesis Testing}

Multiple regression analyses were carried out thrice for hypothesis testing. In the first analysis, each main effect on $\mathrm{P}-\mathrm{O}, \mathrm{P}-\mathrm{T}$, and team-organization cultural fit was tested. In the second analysis, the major effects of each of $\mathrm{P}-\mathrm{O}, \mathrm{P}-\mathrm{T}$, and team-organization cultural fits were tested. The relationships between $\mathrm{P}-\mathrm{O}$ and $\mathrm{P}-\mathrm{T}$ cultural fits and dependent variables were analyzed by inputting control variables in stage one and inputting P-O and P-T cultural fits in stage two to identify the relative effects of P-O and P-T cultural fits. In the third analysis, the moderating role of supportive leadership on the effects of $\mathrm{P}-\mathrm{O}$ and $\mathrm{P}-\mathrm{T}$ cultural fits on dependent variables was examined.

Table 2 presents the results of the analysis of the major effects of the two fits. In the analysis of the effects of the P-O cultural fit on individuals after controlling demographic variables, $\mathrm{P}-\mathrm{O}$ cultural fit was shown to have significant positive effects on both organizational commitment $(\beta=0.15, p<0.001)$ and team commitment $(\beta=0.13, p<0.001)$ except for performance. Therefore, both hypotheses $1 \mathrm{a}$ and $1 \mathrm{~b}$ were supported. However, the correlation between $\mathrm{P}-\mathrm{O}$ cultural fit and job performance was shown to be not significant, indicating that hypothesis $1 \mathrm{c}$ was not supported. P-T cultural fit 
showed significant positive effects on task performance $(\beta=0.06, p<0.01)$, organizational commitment $(\beta=0.18, p<0.001)$, and team commitment $(\beta=0.24, p<0.001)$, indicating that hypotheses $2 \mathrm{a}-\mathrm{c}$ were supported; thus, hypothesis 2 was entirely supported.

Table 2. Effects of P-O and P-T cultural fits.

\begin{tabular}{|c|c|c|c|c|c|c|c|c|c|c|}
\hline & \multicolumn{4}{|c|}{ Organizational Commitment } & \multicolumn{3}{|c|}{ Team Commitment } & \multicolumn{3}{|c|}{ Task Performance } \\
\hline & Model 1 & Model 2 & Model 3 & Model 4 & Model 2 & Model 3 & Model 4 & Model 2 & Model 3 & Model 4 \\
\hline Tenure & 0.03 & 0.02 & 0.01 & 0.01 & -0.01 & -0.03 & -0.03 & 0.24 & $0.22 * * *$ & $0.23^{* * *}$ \\
\hline $\begin{array}{l}\text { Education } \\
\text { level }\end{array}$ & -0.07 & -0.06 & -0.05 & -0.04 & -0.09 & -0.07 & -0.07 & 0.09 & 0.08 & 0.09 \\
\hline $\begin{array}{c}\text { Position } \\
\text { level }\end{array}$ & 0.09 & 0.08 & 0.1 & $0.10^{*}$ & $0.11^{* * *}$ & 0.12 & $0.12 * *$ & $0.24^{* * *}$ & $0.26^{* * *}$ & $0.25^{* * *}$ \\
\hline Gender & 0.07 & 0.07 & 0.07 & $0.07 *$ & 0.08 & 0.08 & $0.07 *$ & 0.00 & -0.01 & -0.01 \\
\hline $\begin{array}{l}\text { Marital } \\
\text { status }\end{array}$ & -0.04 & -0.05 & -0.07 & -0.07 & 0.15 & $0.12^{* * *}$ & $0.12 * *$ & 0.02 & 0.01 & 0.01 \\
\hline $\begin{array}{l}\text { Team } \\
\text { size }\end{array}$ & -0.01 & 0.00 & 0.00 & -0.01 & -0.02 & -0.02 & -0.02 & -0.09 & -0.09 & $-0.09^{* *}$ \\
\hline $\begin{array}{l}\text { Team } \\
\text { tenure }\end{array}$ & -0.01 & -0.01 & 0.01 & 0.01 & -0.09 & -0.07 & -0.07 & $0.11^{* * *}$ & $0.11 * * *$ & $0.11^{* * *}$ \\
\hline $\mathrm{P}-\mathrm{O}$ fit & & $0.15^{* * *}$ & & $0.08^{* *}$ & $0.13^{* * *}$ & & 0.03 & 0.02 & & 0.00 \\
\hline P-T fit & & & $0.18^{* * *}$ & $0.15^{* * *}$ & & $0.24^{* * *}$ & $0.23^{* * *}$ & & $0.06^{*}$ & $0.06^{*}$ \\
\hline$R^{2}$ & & 0.04 & 0.06 & 0.06 & 0.06 & 0.09 & 0.10 & 0.07 & 0.25 & 0.25 \\
\hline$\Delta R^{2}$ & & 0.21 & 0.03 & $0.05^{* * *}$ & 0.02 & 0.06 & $0.06^{* * *}$ & 0.01 & 0 & $0.00^{+}$ \\
\hline F & & $4.76^{* * *}$ & $6.16^{* * *}$ & $5.88^{* * *}$ & $7.06^{* * *}$ & $11.5^{* * *}$ & $10.34^{* * *}$ & $58.06^{* * *}$ & $56.68^{* * *}$ & $50.29^{* * *}$ \\
\hline
\end{tabular}

For the second analysis, a regression was carried out, with P-O cultural fit and P-T cultural fit inputted together with a view to testing the differential effects of the two fits on individuals' attitudes and performance in the organizations. Interesting findings appeared from the analysis. As shown in Table 3, unlike the hypothesis, P-T cultural fit had significant and positive effects on all of the organization-related variables, team-related variables, and task performance, even after P-O cultural fit was inputted. When the value of individuals was congruent with that of their teams, both individuals' team commitment and organizational commitment, as well as their task performance, were shown to be high. However, despite the strong effects of P-T cultural fit, P-O cultural fit still showed significant and positive relationships with organization-related variables, indicating that the congruence between the individuals' values and those of the organization still had effects on organization-related variables rather than on team-related variables. In summary, hypothesis 3a was not supported while hypotheses $3 \mathrm{~b}$ and $3 \mathrm{c}$ were supported.

Table 4 presents the results of the analysis of the moderating effects of supportive leadership. According to the results of the analysis, supportive leadership does not play a significant moderating role in the effects of P-O cultural fit on outcome variables while playing a significant moderating role in the effects of P-T cultural fit on outcome variables. Concretely, P-T cultural fit showed significant moderating effects on team commitment $(\beta=-0.09, p<0.001)$ and organizational commitment $(\beta=-0.07, p<0.01)$. Therefore, hypothesis $4 a$, which indicates the moderating effects on the effects of $\mathrm{P}-\mathrm{O}$ cultural fit on outcome variables, was not supported, while hypothesis $4 \mathrm{~b}$, which is related to the moderating effects on the effects of P-T cultural fit on outcome variables, was supported. 
Table 3. Differential effects of P-O and P-T cultural fits.

\begin{tabular}{ccccc}
\hline \multirow{2}{*}{ Stage } & Variable & $\begin{array}{c}\text { Organizational } \\
\text { Commitment }\end{array}$ & $\begin{array}{c}\text { Team } \\
\text { Commitment }\end{array}$ & Task Performance \\
\hline \multirow{2}{*}{2} & Tenure & 0.01 & -0.03 & $0.23^{* * *}$ \\
\cline { 2 - 5 } & Education level & -0.04 & -0.07 & 0.09 \\
\cline { 2 - 5 } & Position level & $0.10^{*}$ & $0.12^{* *}$ & $0.25^{* * *}$ \\
\cline { 2 - 5 } & Gender & $0.07^{*}$ & $0.07^{*}$ & -0.01 \\
\cline { 2 - 5 } & Marital status & -0.07 & $0.12^{* *}$ & 0.01 \\
\cline { 2 - 5 } & Team size & -0.01 & -0.02 & $-0.09^{* *}$ \\
\cline { 2 - 5 } & Team tenure & 0.01 & -0.07 & $0.11^{* * *}$ \\
\hline & P-O (T1) & $0.08^{* *}$ & 0.03 & 0.00 \\
\hline$R^{2}$ & $0.15^{* * *}$ & $0.23^{* * *}$ & $0.06^{*}$ \\
\hline$R^{2}$ variation & 0.059 & 0.100 & 0.249 \\
\hline$F$ & $0.049^{* * *}$ & $0.057^{* * *}$ & 0.003 \\
\hline
\end{tabular}

Table 4. Effects of P-O and P-T cultural fits.

\begin{tabular}{cccc|ccc}
\hline \multirow{2}{*}{ Variable } & \multicolumn{3}{c|}{ P-O Cultural Fit } & \multicolumn{3}{c}{ P-T Cultural Fit } \\
\cline { 2 - 7 } & $\begin{array}{c}\text { Organizational } \\
\text { Commitment }\end{array}$ & $\begin{array}{c}\text { Team } \\
\text { Commitment }\end{array}$ & $\begin{array}{c}\text { Task } \\
\text { Performance }\end{array}$ & $\begin{array}{c}\text { Organizational } \\
\text { Commitment }\end{array}$ & $\begin{array}{c}\text { Team } \\
\text { Commitment }\end{array}$ & $\begin{array}{c}\text { Task } \\
\text { Performance }\end{array}$ \\
\hline Tenure & 0.02 & -0.02 & 0.23 & 0.03 & -0.02 & 0.22 \\
\hline $\begin{array}{c}\text { Education } \\
\text { level }\end{array}$ & -0.06 & -0.09 & 0.09 & -0.06 & -0.08 & 0.08 \\
\hline Position & 0.07 & 0.08 & 0.24 & 0.07 & 0.08 & 0.25 \\
\hline Gender & 0.06 & 0.06 & -0.01 & 0.06 & 0.06 & -0.01 \\
\hline $\begin{array}{c}\text { Marital } \\
\text { status }\end{array}$ & -0.07 & 0.12 & 0.01 & -0.06 & 0.09 & 0.02 \\
\hline Team size & -0.01 & -0.03 & -0.10 & 0.00 & -0.02 & -0.09 \\
\hline Team tenure & 0.03 & -0.04 & 0.12 & 0.03 & -0.03 & 0.12 \\
\hline Fit(T1) & 0.13 & 0.11 & 0.02 & 0.12 & 0.17 & 0.05 \\
\hline $\begin{array}{c}\text { Supportive } \\
\text { leadership }\end{array}$ & 0.25 & 0.33 & 0.07 & 0.23 & 0.29 & 0.07 \\
\hline $\begin{array}{c}\text { Fitxsupportive } \\
\text { leadership }\end{array}$ & 0.01 & 0.01 & 0.02 & $-0.07 *$ & $-0.09 * *$ & 0.03 \\
\hline$R^{2}$ & 0.10 & 0.16 & 0.25 & 0.10 & 0.18 & 0.25 \\
\hline $1-2 \Delta R^{2}$ & 0.02 & 0.02 & 0.00 & 0.03 & 0.06 & 0.00 \\
\hline $2-3 \Delta R$ & 0.06 & 0.11 & 0.01 & 0.06 & 0.09 & 0.00 \\
\hline
\end{tabular}

Hypothesis 5, regarding the differential outcomes of the analysis of the moderating effects indicating that P-T cultural fit will have the greatest effects on teams, was supported because the effects of P-T cultural fit on team commitment $(B=-0.09, p<0.01)$ were stronger than the effects of $\mathrm{P}-\mathrm{T}$ cultural fit on organizational commitment $(B=-0.07, p<0.05)$. Concrete results regarding the moderating effects are shown in Figure 2. In Figure 2, the left part shows the moderating effects on organizational commitment while the right part shows the moderating effects on team commitment. Although the degrees of significance are different, the same patterns are shown. 

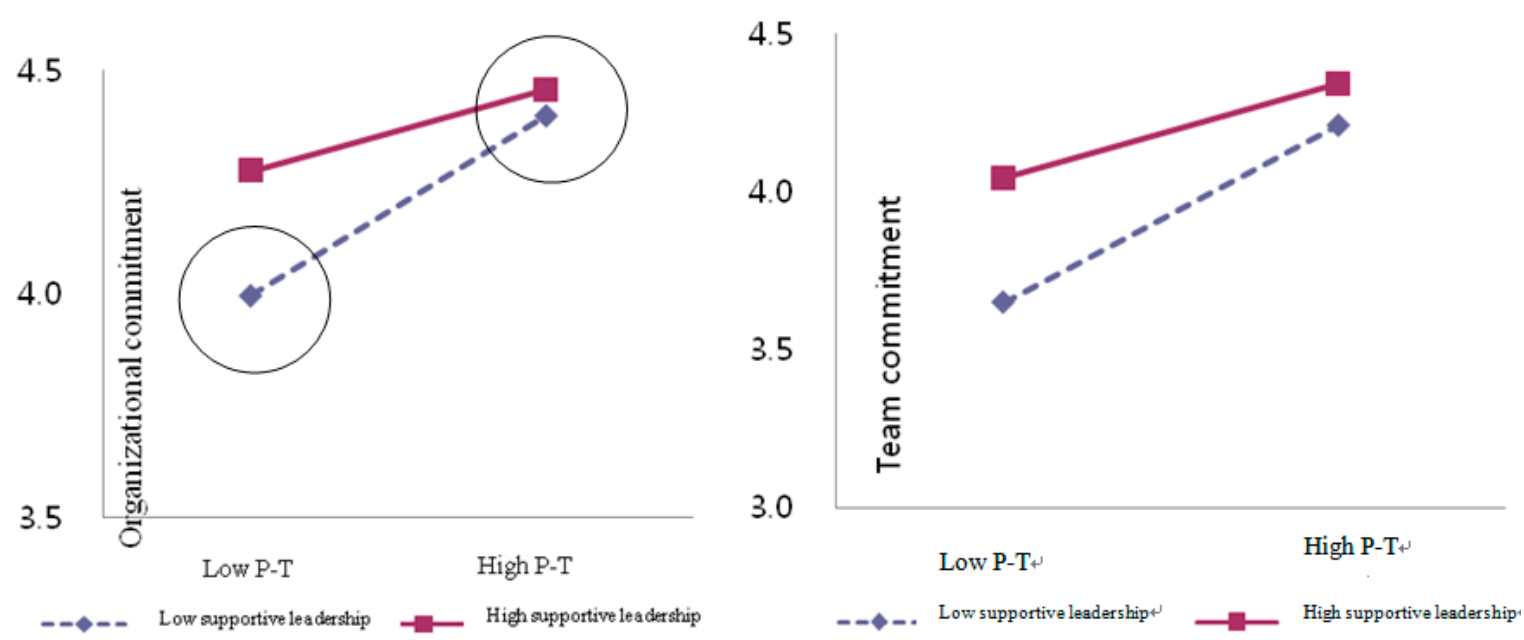

Figure 2. Effects of supportive leadership.

As shown in Figure 2, the levels of organizational commitment and team commitment were shown to be the lowest when levels of supportive leadership and P-T cultural fit were low, while the level of organizational commitment was shown to be high when the level of P-T cultural fit was low while the level of supportive leadership was high. However, some studies show that supportive leadership affects the level of P-T cultural fit. This can be interpreted like the existing moderating effects of POS and LMX suggested earlier, when establishing hypotheses. In addition, the level of supportive leadership also affected outcome variables when the level of P-T cultural fit was high. That is, the highest levels of organizational and team commitment appeared in cases where the level of P-T cultural fit and the level of supportive leadership were both high, indicating that supportive leadership also generates further positive effects.

\section{Discussion}

Values are persistent beliefs personally preferred for certain modes of actions or directives [73]. Existing cultural fit studies have found that the congruence between the values of individuals and those of organizations or teams positively affect individuals (e.g., [25,33,74]). Using longitudinal data obtained through four surveys, the present study was intended to compare P-O cultural fit and P-T cultural fit - which have been consistently reported to have positive effects on individuals' attitudes and behaviors in organizations-in order to empirically identify the differential effects of the two fits on teamand organization-related attitudes and task performance of individuals in organizations, as well as test whether supportive leadership plays a role in strengthening or supplementing these relationships.

The main findings and implications are the following. First, looking at the relationships of each of $\mathrm{P}-\mathrm{O}$ cultural fit and P-T cultural fit with organization-related attitudes (organizational satisfaction, organizational commitment), team-related attitudes (team satisfaction, team commitment), and task performance, P-O cultural fit was shown to have a significant and positive relationship with all variables except task performance. Additionally, individuals were shown to be satisfied with and committed to their organizations and teams when their values were congruent with the values of their organizations. The findings of the present study have shown that P-O cultural fit can affect not only individuals' attitudes toward their organization but also their attitudes toward their teams.

Second, P-T cultural fit showed positive effects on both individuals' attitudes toward their teams and their attitudes toward organizations, including individuals' performance. Although P-T cultural fit studies are on the rise [2,45], studies that examine the effects of P-T cultural fit on individuals through diverse outcome variables have been scarce. In this respect, the focus on P-T cultural fit can be said to widen the breadth of studies. In particular, in the present study, the relationship between P-T cultural fit and organization-related variables, which have hardly been examined in existing P-T cultural fit 
studies, were taken into account to identify whether the congruence between individuals' values and the values of their team was related to organizations. As a result, it was shown that P-T cultural fit has significant effects on both organizational satisfaction and organizational commitment, including the values of the organizations, and that the congruence between individuals' values and the values of their team makes the individuals have positive attitudes toward their organizations.

Third, in the present study, P-T cultural fit showed stronger correlations than P-O cultural fit with all the variables that have significant and positive effects on all the outcome variables examined in the present study. This is consistent with the argument of Adkins and Caldwell that the roles of autonomous teams will be continuously increased due to the dynamics of the organizational environments, so that teams will have major effects on individuals' lives within organizations [1]. The change from lifelong workplaces to lifelong occupations is also an organizational element that leads to further emphasis on the importance of teams rather than organizations. In particular, the target companies based on which the present study was conducted can be said to be organizations in which team unit works and in which team systems have been established due to the characteristics of the engineering business. Therefore, the findings of the present study reflected the importance of teams, and the finding that the congruence between individuals' values and that of their team is important not only for individuals' attitudes toward their team but also their attitudes toward their organization, which can be said to carry important implications for organization management. Managers of organizations should consider the fact that they can further contribute to organizational commitment and the creation of positive outcomes by seeking methods of active team management.

Fourth, it was found that P-O cultural fit was still affecting organization-related variables even after P-T cultural fit was counted. Team culture can reflect the organizational culture while forming an independent culture. This means that in order to create commitment to and satisfaction with the organization per se, rather than simply relying on the congruence between individual and team values, the values of the organization should also be managed. Recently, many organizations have formed a team dealing with organizational culture within each organization. Each organization should manage the culture of the entire organization, as well as the cultures of lower level unit organizations, to make sure that employees have positive attitudes toward the organization.

Fifth, team leaders' supportive leadership had moderating effects in the relationship between $\mathrm{P}-\mathrm{T}$ cultural fit and organizational commitment, team satisfaction, and team commitment. This is consistent with the findings indicating that P-T cultural fit has a strong effect on individuals' attitudes and performance in organizations, suggesting that to further enhance or supplement the effects of fits on individuals, team leaders' supportive leadership, such as care and consideration, should be implemented. To further amplify the positive effects brought about by the congruence of individuals' and organizations' values in the continuous changes toward team-centered organizations, appropriate orientation and education should be provided for team leaders.

In addition, as predicted in the hypothesis, the moderating effects of team leaders' supportive leadership were shown to affect not only team satisfaction and team commitment but also organizational commitment (although not as strong as the effects on team satisfaction and team commitment). This means that the results of team dynamics, such as team leaders' supportive leadership and the congruence of individuals' values with those of their team affect individuals' attitudes toward organizations too. Since these findings show that management of and effects on teams can influence individuals' attitudes toward organizations, they can be said to stress the importance of team management and dynamics once again. In future studies, the exploration of diverse control and mediating variables, and variables that affect teams and attitudes toward the organization seems to be possible.

Sixth, the moderating effects of team leaders' supportive leadership did not significantly affect the effects of P-T cultural fit on task performance. In the present study, supportive leadership was defined as providing emotional support and responding to members' desires and needs [48,57]. It was suggested that such psychological support would also affect task performance. However, supportive 
leadership had significant effects on individuals' attitudes toward their organization but did not significantly affect task performance. Therefore, supportive leadership can be interpreted to further affect attitude rather than being directly related to task performance. Existing organization behavior studies showed that positive attitudes in organizations significantly predict performance [75-77]. In relation to the effect of leadership, the types of incentives that leaders have from their organization should be examined as well, especially in the sustainable management. Dunbar, Li, and Shi [78] examined the effect of CSR standing on CEO's future risk-taking financial incentives and found that firms with better social performance generate insurance-like moral capital that reduces firm risk, so the leaders have more risk-taking capacity. These leaders can offer greater risk-motivating incentives to team leaders, so that supportive leaders with more risk-motivating incentives can further encourage their team members to work better, yielding higher level of task performance. Therefore, in future studies, whether individuals' attitudes toward their team and organization significantly affect their task performance should be examined to see whether the effects of supportive leadership can be extended to performance.

Despite these theoretical and practical implications, the present study involves limitations that require further development. First, although the present study minimizes the same variance polarization through the longitudinal design, the timing of the longitudinal design, which was based on two-month units, can be said to be rather short. Since the long-term effects of P-O or P-T fit is an important question for adaptation to and satisfaction with organizations, in future studies, the effects brought about by fits should be analyzed in six-month or one-year units.

Second, the present study can be said to be meaningful in that multiple outcome variables were used for teams, organizations, and performance, as integrated comparisons of P-O cultural fit and P-T cultural fit had created somewhat mixed results previously. However, since the tools used in the present study were items for consciousness surveys or organizational culture surveys used in actual organizations, most items were measured in abbreviated forms. Therefore, it can be said that items for scales should be further expanded in order to secure the reliability of outcome variables.

Third, the effects of cultural fit on the outcome variables at the individual level were examined through comparison between the two fits. However, the relationships between the diverse control and outcome variables mentioned in fits were not fully examined. In future studies, various control variables expected to affect cultural fit should be examined together.

For the corporate sustainability, fundamental organizational culture based on social and environmental responsibility, as well as training leaders and managers, as models according to those values are crucial [79]. Adherence to those core values and leadership enactment compatible with organizational culture can be the important culture development process improving P-O fit and P-T fit. Employees with good fit with their team and organization in terms of their social values will form positive attitudes towards organizations' social activity and work proactively, which will bring higher social, as well as financial, return for the organization.

Author Contributions: J.Y.L. developed research idea, and collected and analyzed data. Y.S. further analyzed data and revised the draft for publication.

Funding: This research was funded by Hansung University.

Conflicts of Interest: The authors declare no conflict of interest.

\section{References}

1. Adkins, B.; Caldwell, D. Firm or subgroup culture: Where does fitting in matter most? J. Organ. Behav. 2004, 25, 969-978. [CrossRef]

2. Kristof-Brown, A.L.; Zimmerman, R.D.; Johnson, E.C. Consequences of Individuals' Fit at work: A meta-analysis of person-job, person-organization, person-group, and person-supervisor fit. Pers. Psychol. 2005, 58, 281-342. [CrossRef] 
3. Kristof-Brown, A.L. Person-organization fit: An integrative review of its conceptualizations, measurement, and implications. Pers. Psychol. 1996, 49, 1-49. [CrossRef]

4. Sekiguchi, T. Person-organization fit and person-job fit in employee selection: A review of the literature. Osaka Keidai Ronshu. 2004, 54, 179-196.

5. Seong, J.Y.; Kristof-Brown, A.L.; Park, W.-W.; Hong, D.-S.; Shin, Y. Person-Group fit: Diversity antecedents, proximal outcomes, and performance at the group level. J. Manag. 2015, 41, 1184-1213. [CrossRef]

6. Verquer, M.L. Fitting in at Work: A Comparison of the Relationships Between Person-Organization Fit and Person-Group Fit with Work Attitudes. Ph.D. Thesis, ProQuest Information \& Learning, Ann Arbor, MI, USA, 2002.

7. Werbel, J.D.; Johnson, D.J. The use of person-group fit for employment selection: A missing link in person-environment fit. Hum. Resour. Manag. 2001, 40, 227-240. [CrossRef]

8. Greguras, G.J.; Diefendorff, J.M. Different fits satisfy different needs: Linking person-environment fit to employee commitment and performance using self-determination theory. J. Appl. Psychol. 2009, 94, 465-477. [CrossRef]

9. Vogel, R.M.; Feldman, D.C. Integrating the levels of person-environment fit: The roles of vocational fit and group fit. J. Vocat. Behav. 2009, 75, 68-81. [CrossRef]

10. Lauver, K.J.; Kristof-Brown, A. Distinguishing between employees' perceptions of person-job and person-organization fit. J. Vocat. Behav. 2001, 59, 454-470. [CrossRef]

11. Shin, Y.H. Effects of team-level person-organization and person-job fit on team organizational citizenship behaviors and team efficacy. Korean Acad. Manag. 2008, 16, 1-15.

12. Cable, D.M.; DeRue, D.S. The convergent and discriminant validity of subjective fit perceptions. J. Appl. Psychol. 2002, 87, 875-884. [CrossRef] [PubMed]

13. Saks, A.M.; Ashforth, B.E. Organizational socialization: Making sense of the past and present as a prologue for the future. J. Vocat. Behav. 1997, 51, 234-279. [CrossRef]

14. Ilgen, D.R. Teams embedded in organizations: Some implications. Am. Psychol. 1999, 54, 129-139. [CrossRef]

15. Ferris, G.R.; Youngblood, S.A.; Yates, V.L. Personality, training performance, and withdrawal: A test of the person-group fit hypothesis for organizational newcomers. J. Vocat. Behav. 1985, 27, 377-388. [CrossRef]

16. Hollenbeck, J.R.; Moon, H.; Ellis, A.P.; West, B.J.; Ilgen, D.R.; Sheppard, L.; Wagner, J.A., III. Structural contingency theory and individual differences: Examination of external and internal person-team fit. J. Appl. Psychol. 2002, 87, 599-606. [CrossRef]

17. Kristof-Brown, A.; Barrick, M.R.; Kay Stevens, C. When opposites attract: A multi-sample demonstration of complementary person-team fit on extraversion. J. Pers. 2005, 73, 935-958. [CrossRef]

18. Zaccaro, S.J.; Rittman, A.L.; Marks, M.A. Team leadership. Leadersh. Q. 2001, 12, 451-483. [CrossRef]

19. Oo, E.; Jung, H.; Park, I.J. Psychological factors linking perceived CSR to OCB: the role of organizational pride, collectivism, and person-organization fit. Sustainability 2018, 10, 2481. [CrossRef]

20. Lee, M.; Kim, H. Exploring the organizational culture's moderating role of effects of Corporate Social Responsibility (CSR) on firm performance: Focused on corporate contributions in Korea. Sustainability 2017, 9, 1883. [CrossRef]

21. Bezrukova, K.; Thatcher, S.M.B.; Jehn, K.A.; Spell, C.S. The effects of alignments: Examining group faultlines, organizational cultures, and performance. J. Appl. Psychol. 2011, 97, 77-92. [CrossRef]

22. O'Reilly, C.A.; Chatman, J.; Caldwell, D.F. People and organizational culture: A profile comparison approach to assessing person-organization fit. Acad. Manag. J. 1991, 34, 487-516.

23. Van Knippenberg, D.; Schippers, M.C. Work group diversity. Annu. Rev. Psychol. 2007, 58, 515-541. [CrossRef] [PubMed]

24. Adkins, C.L.; Russell, C.J.; Werbel, J.D. Judgments of fit in the selection process: The role of work value congruence. Pers. Psych. 1994, 47, 605-623. [CrossRef]

25. Boxx, W.R. Organizational values and value congruency and their impact on satisfaction, commitment, and cohesion: An empirical examination within the public sector. Public Pers. Manag. 1991, 20, 195-205. [CrossRef]

26. Chatman, J.A. Improving interactional organizational research: A model of person-organization fit. Acad. Manag. Rev. 1989, 14, 333-349. [CrossRef]

27. Chatman, J.A. Matching people and organizations: Selection and socialization in public accounting firms. Admin. Sci. Q. 1991, 36, 459-484. [CrossRef] 
28. Caldwell, D.F.; O'Reilly, C.A., III. Measuring person-job fit with a profile-comparison process. J. Appl. Psychol. 1990, 75, 648-657. [CrossRef]

29. Saffold, G.S. Culture traits, strength, and organizational performance: Moving beyond "strong" culture. Acad. Manag. Rev. 1988, 13, 546-558.

30. Resick, C.J.; Baltes, B.B.; Shantz, C.W. Person-organization fit and work-related attitudes and decisions: Examining interactive effects with job fit and conscientiousness. J. Appl. Psychol. 2007, 92, 1446-1455. [CrossRef]

31. Gruman, J.A.; Saks, A.M.; Zweig, D.I. Organizational socialization tactics and newcomer proactive behaviors: An integrative study. J. Vocat. Behav. 2006, 69, 90-104. [CrossRef]

32. Saks, A.M.; Ashforth, B.E. Is job search related to employment quality? It all depends on the fit. J. Appl. Psychol. 2002, 87, 646-654. [CrossRef] [PubMed]

33. Verquer, M.L.; Beehr, T.A.; Wagner, S.H. A meta-analysis of relations between person-organization fit and work attitudes. J. Vocat. Behav. 2003, 63, 473-489. [CrossRef]

34. Byrne, D.E. The Attraction Paradigm; Academic Press: Cambridge, MA, USA, 1971; Volume 11.

35. Hogg, M.A. Social identity theory. Contemp. Soc. Psychol. Theor. 2006, 13, 111-1369.

36. Ostroff, C.; Shin, Y.; Kinicki, A.J. Multiple perspectives of congruence: Relationships between value congruence and employee attitudes. J. Organ. Behav. 2005, 26, 591-623. [CrossRef]

37. Boisnier, A.; Chatman, J.A. Cultures and subcultures in dynamic organizations. Dynamic Org. 2003, 87-114.

38. Fried, Y.; Ferris, G.R. The validity of the job characteristics model: A review and meta-analysis. Pers. Psychol. 1987, 40, 287-322. [CrossRef]

39. Hoffman, B.J.; Woehr, D.J. A quantitative review of the relationship between person-organization fit and behavioral outcomes. J. Vocat. Behav. 2006, 68, 389-399. [CrossRef]

40. Deci, E.L.; Ryan, R.M. Self-Determination theory. Int. Encycl. Soc. Behav. Sci. 2011, 1, 416-433.

41. Argyris, C. Personality and Organization: The Conflict between System and the Individual; Harpers: Oxford, UK, 1957.

42. Adkins, C.L.; Ravlin, E.C.; Meglino, B.M. Value congruence between co-workers and its relationship to work outcomes. Group Organ. Manag. 1996, 21, 439-460. [CrossRef]

43. Elfenbein, H.A.; O'Reilly, C.A. Fitting in: The effects of relational demography and person-culture fit on group process and performance. Group Organ. Manag. 2007, 32, 109-142. [CrossRef]

44. Seong, J.Y.; Kristof-Brown, A.L. Testing multidimensional models of person-group fit. J. Manage. Psychol. 2012, 27, 536-556. [CrossRef]

45. DeRue, D.S.; Morgeson, F.P. Stability and change in person-team and person-role fit over time: The effects of growth satisfaction, performance, and general self-efficacy. J. Appl. Psychol. 2007, 92, 1242-1253. [CrossRef] [PubMed]

46. Cameron, K.S.; Quinn, R.E. Diagnosing and Changing Organizational Culture: Based on the Competing Values Framework; Jossey-Bass: San Francisco, CA, USA, 2006.

47. Kozlowski, S.W.; Bell, B.S. Work Groups and Teams in Organizations. Handbook of Psychology; Wiley: London, UK, 2003.

48. Rafferty, A.E.; Griffin, M.A. Dimensions of transformational leadership: Conceptual and empirical extensions. Leadership. Q. 2004, 15, 329-354. [CrossRef]

49. Kirkman, B.L.; Rosen, B. Beyond self-management: Antecedents and consequences of team empowerment. Acad. Manag. J. 1999, 42, 58-74.

50. Erdogan, B.; Kraimer, M.L.; Liden, R.C. Person-Organization fit and work attitudes: The moderating role of leader-member exchange. Acad. Manag. Proc. 2017, 2002, F1-F6. [CrossRef]

51. Maden, C.; Kabasakal, H. The simultaneous effects of fit with organizations, jobs and supervisors on major employee outcomes in Turkish banks: Does organizational support matter? Int. J. Hum. Resour. Manag. 2014, 25, 341-366. [CrossRef]

52. Erdogan, B.; Kraimer, M.L.; Liden, R.C. Work value congruence and intrinsic career success: The compensatory roles of leader-member exchange and perceived organizational support. Pers. Psych. 2004, 57, 305-332. [CrossRef]

53. Day, D.V.; Gronn, P.; Salas, E. Leadership in team-based organizations: On the threshold of a new era. Leadersh. Q. 2006, 17, 211-216. [CrossRef] 
54. Euwema, M.C.; Wendt, H.; Van Emmerik, H. Leadership styles and group organizational citizenship behavior across cultures. J. Organ. Behav. 2007, 28, 1035-1057. [CrossRef]

55. Porras, J.I.; Anderson, B. Improving managerial effectiveness through modeling-based training. Organ. Dyn. 1981, 9, 60-77. [CrossRef]

56. Wikoff, M.; Anderson, D.C.; Crowell, C.R. Behavior management in a factory setting: Increasing work efficiency. J. Organ. Behav. 1983, 4, 97-128. [CrossRef]

57. Rafferty, A.E.; Griffin, M.A. Refining individualized consideration: Distinguishing developmental leadership and supportive leadership. J. Occup. Organ. Psychol. 2006, 79, 37-61. [CrossRef]

58. Cohen, S.; Wills, T.A. Stress, social support, and the buffering hypothesis. Psychol. Bull. 1985, 98, 310-357. [CrossRef] [PubMed]

59. House, R.J. A path goal theory of leader effectiveness. Admin. Sci. Q. 1971, 16, 321-339. [CrossRef]

60. Kuvaas, B.; Buch, R.; Dysvik, A.; Haerem, T. Economic and social leader-member exchange relationships and follower performance. Leadersh. Q. 2012, 23, 756-765. [CrossRef]

61. Druskat, V.U.; Wheeler, J.V. Managing from the boundary: The effective leadership of self-managing work teams. Acad. Manag. J. 2003, 46, 435-457.

62. Bishop, J.W.; Scott, K.D.; Burroughs, S.M. Support, commitment, and employee outcomes in a team environment. J. Manag. 2000, 26, 1113-1132. [CrossRef]

63. Neininger, A.; Lehmann-Willenbrock, N.; Kauffeld, S.; Henschel, A. Effects of team and organizational commitment-A longitudinal study. J. Vocat. Behav. 2010, 76, 567-579. [CrossRef]

64. Fishbein, M.; Ajzen, I. Intention and Behavior: An Introduction to Theory and Research; Addison-Wesley: Boston, MA, USA, 1975.

65. Hartnell, C.A.; Ou, A.Y.; Kinicki, A. Organizational culture and organizational effectiveness: A meta-analytic investigation of the competing values framework's theoretical suppositions. J. Appl. Psychol. 2011, 96, 677-694. [CrossRef]

66. Sheridan, T.B. Telerobotics, Automation, and Human Supervisory Control; MIT Press: Cambridge, MA, USA, 1992.

67. Vandenberghe, C. Organizational culture, person-culture fit, and turnover: A replication in the health care industry. J. Organ. Behav. 1999, 20, 175-184. [CrossRef]

68. Allen, N.J.; Meyer, J.P. Affective, continuance, and normative commitment to the organization: An examination of construct validity. J. Vocat. Behav. 1996, 49, 252-276. [CrossRef]

69. Campion, M.A.; Medsker, G.J.; Higgs, A.C. Relations between work group characteristics and effectiveness: Implications for designing effective work groups. Pers. Psychol. 1993, 46, 823-850. [CrossRef]

70. House, R.J. Path-Goal theory of leadership: Lessons, legacy, and a reformulated theory. Leadersh. Q. 1996, 7, 323-352. [CrossRef]

71. Li, Z.F. Mutual monitoring and corporate governance. J. Bank. Financ. 2014, 45, 255-269.

72. Sun, R.; Peng, S.; Pandey, S.K. Testing the effect of person-environment fit on employee perceptions of organizational goal ambiguity. Public Perform. Manag. Rev. 2014, 37, 465-495. [CrossRef]

73. Rokeach, M. The Nature of Human Values; Free Press: New York, NY, USA, 1973.

74. Edwards, J.R.; Cable, D.M. The value of value congruence. J. Appl. Psychol. 2009, 94, 654-667. [CrossRef]

75. Bishop, J.W.; Scott, D. How commitment affects team performance. HR Magazine 1997, 42, 107-111.

76. Meyer, J.P.; Paunonen, S.V.; Gellatly, I.R.; Goffin, R.D.; Jackson, D.N. Organizational commitment and job performance: It's the nature of the commitment that counts. J. Appl. Psychol. 1989, 74, 152-156. [CrossRef]

77. Riketta, M. Attitudinal organizational commitment and job performance: A meta-analysis. J. Organ. Behav. 2002, 23, 257-266. [CrossRef]

78. Dunbar, C.G.; Li, Z.F.; Shi, Y. Corporate social responsibility and CEO risk-taking incentives. SSRN 2017. [CrossRef]

79. Ketprapakorn, N.; Kantabutra, S. Culture Development for Sustainable SMEs: Toward a Behavioral Theory. Sustainability 2019, 11, 2629. [CrossRef]

(C) 2019 by the authors. Licensee MDPI, Basel, Switzerland. This article is an open access article distributed under the terms and conditions of the Creative Commons Attribution (CC BY) license (http://creativecommons.org/licenses/by/4.0/). 